\title{
Juventude e participação na escola: Disputas e relações no cotidiano escolar
}

\section{Youth and participation at school: Disputes and relationships in everyday school life}

\author{
DOI: $10.46814 / \operatorname{lajdv4n1-012}$
}

Recebimento dos originais: 01/01/2021

Aceitação para publicação: 28/02/2022

\section{Francisco André Silva Martins}

Professor da Faculdade de Educação da Universidade do Estado de Minas Gerais e do Programa de Pós Graduação Mestrado Acadêmico em Educação e Formação Humana - FaE-UEMG.

Doutor em Educação pela FaE-UFMG.

Coordenador do Observatório das Juventudes da FaE-UEMG.

E-mail: francisco.martins@uemg.br

Juarez Tarcísio Dayrell

Professor adjunto da Fae-UFMG e orientador da pesquisa de mestrado.

E-mail: juareztd@uol.com.br

\section{RESUMO}

O presente trabalho tem como objetivo discutir as relações estabelecidas entre os jovens do grêmio estudantil, os professores e a direção de uma escola pública de ensino médio. O intuito do artigo está em perceber as tensões decorrentes da participação do estudante em seu cotidiano escolar, bem como, os reflexos dessa experiência. As questões suscitadas caminham no sentido de perceber que o processo participativo escolar é perpassado por disputas entre sujeitos que defendem interesses, muitas vezes, distintos. O funcionamento da escola, por vezes, contempla o "ser aluno" e tal imagem pode não ser condizente com a participação dos jovens no cotidiano escolar. O processo de atuação dos jovens gremistas provoca uma tensão entre lógicas distintas: a dinâmica dos jovens e a estrutura da escola. Como um espaço socializador, com dinâmica própria, o grêmio e as atividades promovidas pelos jovens gremistas, podem sinalizar um caminho importante para a quebra de estereótipos e para uma atuação diferenciada do estudante em seu processo de formação escolar.

Palavras-chave: Juventude, Participação, Relação Direção/Estudantes.

\section{ABSTRACT}

This paper aims to discuss the relationships established among the students of the student's guild, the teachers and the board of directors of a public high school. The purpose of the article is to understand the tensions resulting from the student's participation in their daily school life, as well as the consequences of this experience. The questions raised are related to the fact that the school participatory process is permeated by disputes between subjects who defend different interests. The school operation, at times, contemplates the "being a student" and such image may not be consistent with the participation of young people in the school routine. The process of action of the young gremistas causes a tension between different logics: the dynamics of young people and the structure of the school. As a socializing space, with its own dynamics, the soccer club and the activities promoted by the young gremista members can signal an important path to break stereotypes and to a differentiated performance of the student in his school formation process. 
Keywords: Youth, Participation, Management-Students Relationship.

\section{CONSIDERAÇÕES INICIAIS}

O presente trabalho surge dos esforços empreendidos em uma pesquisa de mestrado desenvolvida na Faculdade de Educação da Universidade Federal de Minas Gerais intitulada “A voz do estudante na educação pública: um estudo sobre participação de jovens por meio de grêmio estudantil”. O objetivo é empreender uma discussão em torno das relações estabelecidas entre jovens, direção escolar e professores, tendo como pano de fundo o processo participativo inerente à atuação do grêmio estudantil em uma escola pública de ensino médio. A escola estudada compõe uma Fundação que funciona sob os cuidados de um município da Região Metropolitana de Belo Horizonte.

Em se tratando de procedimento metodológico, foi empreendido um Estudo de Caso, em que a abordagem qualitativa teve como principais ferramentas metodológicas a observação participante e o desenvolvimento de entrevistas semi-estruturadas. A tentativa é de caminhar no sentido de contribuir para ampliar o conhecimento já produzido sobre a juventude, principalmente, no que tange as relações, disputas cotidianas e experiências participativas vividas pelos jovens na escola.

\section{PARTICIPAÇÃO NA ESCOLA}

Inicialmente, é importante estabelecermos algumas discussões em torno do exercício participativo por parte do estudante no cotidiano escolar. Essas relações são perpassadas por tensões decorrentes, muitas vezes, de imagens construídas historicamente, tanto no que se refere à escola, quanto no que se refere ao aluno (SACRISTAN, 2005). Nesse aspecto, podem ocorrer situações de embate entre a tradição e a inovação. De acordo com Ana Paula Corti e Raquel Souza "quando pensamos em como a escola costuma focalizar e tratar os jovens, percebemos logo que predomina a categoria aluno" (2004, p.118).

Entretanto, apesar da homogeneidade histórica nos protocolos do "ser aluno" a condição de aluno é vivida de forma desigual e diversa em virtude da classe social, do gênero, da raça, dentre outros aspectos. Sacristan (2005) salienta que "essa precaução diante da heterogeneidade da experiência escolar deve nos levar a um entendimento diversificado sobre o que significa ser aluno como indivíduo" (p.126). Diante disso, pensar a participação do estudante na escola pode envolver mudanças que suplantam o que antes era determinado para essa categoria. De acordo com Sacristan (2005) “o ser que está na sala de aula, tal como agora conhecemos e representamos, é uma invenção tardia que surge com o desenvolvimento dos sistemas escolares" (p.125). 
Assim, vislumbramos que a relação entre a participação do jovem na escola e o "ser aluno" pode estar envolvida pelo receio para com a mudança, para com o novo, para com a quebra de valores, comportamentos e regras. Entretanto, o exercício participativo vivido pelo jovem pode contemplar o que Abramo (2004) vai chamar de Socialização Satisfatória, como um processo de aprendizado e formação que vai além da educação formal. O conhecimento, nesse aspecto, se dá pelo seu próprio processo construtivo, é caleidoscópico e ininterrupto.

De posse dos aspectos levantados, compactuamos com o que nos traz Jeannete Ramos (2005) ao estudar a gestão democrática da escola pública, a autora salienta que "a educação é contraditória, comportando ao mesmo tempo conservação e inovação, podendo servir para reproduzir as injustiças, mas, concomitantemente, funcionar como instrumento de mudanças" (p.41). Na escola estudada pudemos perceber aspectos importantes no que tange a participação juvenil no cotidiano escolar que se apresentam na relação dos jovens com a direção da escola e com os professores.

\section{A RELAÇÃO COM A DIREÇÃO DA ESCOLA}

Um dos pontos importantes referentes à participação do jovem na escola está vinculado à relação estabelecida com o seu diretor. $\mathrm{Na}$ escola estudada essa relação é perpassada por tensões inerentes ao processo de democratização da escola. Ao nos propormos a investigar o grêmio estudantil e as experiências proporcionadas aos estudantes nele envolvidos reconhecemos ser de vital importância perpassar, inicialmente, por uma discussão que contemple os princípios da gestão democrática da escola (OLIVEIRA, 2006; RAMOS, 2005). Mesmo que esse não seja o foco principal do presente trabalho, cremos que a discussão seja vital no processo de inserção e reconhecimento do estudante como ator singular no processo educacional.

A Constituição Federal de 1988 e posteriormente de maneira mais efetiva a Lei de Diretrizes e Bases da Educação Nacional, de 20 de dezembro de 1996, trazem à baila novas possibilidades no que concerne à autonomia e participação da gestão escolar, para professores, pais e estudantes. Contudo, também é necessário argumentar em que medida essa democratização da escola, atualmente, contempla o estudante como um ator com direito a participação efetiva no cotidiano escolar. Segundo Bessa et. al. ([s.n.t.]):

A democratização do processo de gestão deve garantir, através do exercício permanente de análise e de ações participativas o acesso igualitário às informações a todos os segmentos da comunidade escolar e a aceitação da diversidade de opiniões e interesses. Dentro desse contexto, o Grêmio estudantil vem se constituindo como excelente dispositivo para a concretização de um processo mais solidário entre os diversos grupos (BESSA et. al., [s.n.t.], p. 3). 
É importante considerar a existência de uma distância considerável entre o que é legalmente determinado e o que realmente ocorre no cotidiano das escolas. Na atual conjuntura da educação brasileira faz-se necessário abrir novos caminhos para a gestão democrática, no que se refere ao “diálogo como forma superior de encontro das pessoas e soluções de conflitos” (CURY, 2006).

As premissas de uma gestão escolar dialogam com tendências democráticas atualmente percebidas na eleição de diretores, políticas públicas de universalização do ensino, implementação de projetos, descentralização de decisões e obrigações, além da busca da autonomia escolar de acordo com suas singularidades (OLIVEIRA, 2006). Apesar dessas tendências, que podem ser consideradas avanços, é necessário ressaltar que ainda há muito o que fazer. Há que se reconhecer que "nos avanços da gestão democrática, a presença e voz dos alunos muito pouco avançou" (ARROYO, 2005, p. 42). Passados alguns anos desde a LDB de 1996, novas abordagens do problema se fazem necessárias para interpretação dos caminhos possíveis a serem seguidos.

Nesse artigo ao tratar da relação estabelecida entre a direção e os jovens do grêmio percebemos que essa é marcada pela defesa de posições e interesses distintos. Em função da distinção os jovens se posicionam de forma antagônica à direção. Tomando como base os estudos de Alberto Melucci (1989, 2001, 2004) no que referente aos movimentos sociais, entendemos o grêmio como uma área de atuação do movimento estudantil e esperamos jogar luz sobre alguns pontos importantes. A atuação dos jovens está ligada a uma ação coletiva que se relaciona a objetivos, recursos e limites. Nesse sentido, o antagonismo estabelecido decorre de uma identidade coletiva formada pelos jovens como estudantes que se mostram solidários em seus anseios (MELUCCI, 2004, 2001).

Na escola, entendida como arena de disputas, há uma tendência à formação de um "NÓS", que agrega os interesses dos estudantes, e dos "OUTROS", que comporta os demais atores que não os estudantes. De acordo com um dos jovens entrevistados, Felipe ${ }^{1}$, os jovens do grêmio já foram inclusive "chamados de partido contrário, contrário do que eles falavam (direção)... oposição" (Felipe, 16 anos). Em oposição aos "OUTROS" o "NÓS" sustenta uma identidade coletiva como um sistema de ação do grupo. Nesse processo de disputa alguns jovens do grêmio se posicionam de maneira mais incisiva e a direção acaba por assumir junto a esses jovens o papel de "inimigo" a ser combatido, Rodrigo, um outro jovem escutado na pesquisa, considera que "o grêmio estudantil tá ali sempre... pra tocar na ferida, o grêmio estudantil não tá nem aí, tá querendo... quer ferrar com o diretor em todos... nos pontos negativos dele, em tudo!" (Rodrigo, 16 anos).

\footnotetext{
${ }^{1}$ Foram utilizados nomes fictícios com o intuito de manter a privacidade dos sujeitos envolvidos na pesquisa, evitando assim uma possível identificação por parte dos leitores do trabalho. Tal prática caminha no sentido de obedecer aos procedimentos éticos estabelecidos pelo Comitê de Ética em Pesquisa da Universidade Federal de Minas Gerais (COEPUFMG).
} 
Como foi sinalizado, a tensão vivida no cotidiano da escola está ligada a lógicas distintas, a uma direção que tem como caráter central administrar a escola e lidar com a burocracia inerente desse processo e ao grêmio e seus jovens que ao vivenciarem a condição juvenil têm anseios urgentes, são dinâmicos e vivem em uma sociedade do presente, na qual tudo se resolve no agora. O tempo interno do jovem e o tempo social da escola se divergem, há o conflito entre o desejo e a linearidade (MELUCCI, 2001). Em função do imediatismo e da urgência inerentes da condição juvenil a procura é por um melhor aproveitamento desse tempo (GIDDENS, 2002).

Apropriamos-nos da metáfora concretizada por Corti e Souza (2004), ao tratar do mundo Escolar e do mundo Juvenil, para dar continuidade à discussão. Assim como os tempos são dissonantes, os mundos e, consequentemente, as experiências, também o são. Os mundos ao se dividirem em Escolar e Juvenil, demarcam a fronteira entre a estrutura rígida da escola e a dinâmica inerente à vivência da juventude. Assim, esses estabelecem uma relação dicotômica, distante, por vezes antagônica. Essa distância tende a dificultar o processo educacional escolar, privilegiando muitas vezes uma estrutura rígida em detrimento do que poderia se tornar dinâmico.

Nesse contexto, de disputas e tensões, a administração do diretor é vista pelos jovens como sendo morosa, devagar, causadora de embargo as atividades do grêmio. O diretor ao tratar do fato relata que "eles já me falaram isso, que eu sou ausente, você tá entendendo, e eu não concordo com eles, agora provavelmente eles falam isso porque eu não dou conta, e aí eu tô falando no nome da escola, de resolver as demandas por parte deles" (Diretor da escola). A ausência levantada pelos estudantes e ressaltada pelo diretor parece se relacionar com as questões relativas ao grêmio, a administração tem obrigações que por vezes podem impedir uma maior atenção, daí as críticas feitas pelos jovens. Quanto à "não dar conta" da resolução das demandas, esse é um ponto de conflito entre as expectativas dos jovens e a capacidade de interação e resolução da administração.

Contudo, há que ressaltar que a participação também demanda uma capacidade de lidar com a negação. Nem tudo que for proposto pelo grêmio vai ser aprovado, e mais do que isso, essa negação pode funcionar também como parâmetro para delimitação de fronteiras e percepção de instâncias de atuação. De acordo com Moreira (2001) através desse processo "pode-se analisar o desenvolvimento das capacidades de administração e de negociação, que o relacionamento com a direção proporciona" (p.102).

Em se tratando da relação estabelecida com a direção e a participação na escola os jovens consideram que sempre prevalece à visão da escola. Sobre essa questão, Karine comenta, "a gente é chamado pela escola, quando a importância é mínima" (Karine, 16 anos). A jovem deixa transparecer que, em sua opinião, a participação dos jovens não é devidamente valorizada pela direção da escola. A respeito da relação vivida entre o grêmio e a direção Andresa, uma das estudantes, ressalta: 
É totalmente de momentos de tensões. Acho que é, é porque o grupo assim passa, sei lá, aquela, que eu acho que não deveria ser assim, por causa que o grêmio no caso é uma autoridade dentro da escola, no caso eles (Direção) também. Mas acaba não tendo aquele, aquele nível assim de todo mundo igual, acaba eles de alguma maneira, sendo superiores ${ }^{2}$ e fica aquela coisa assim não tem aquela relação.(Andresa, 16 anos).

O grêmio é mais uma das instituições colegiadas dentro da escola e tem seu papel no que se refere à representação do estudante (MARTINS, 2009). De acordo com Carlos (2006) o grêmio pode funcionar como "grupo de pressão, forçando a instituição escolar a reconhecer espaços legítimos de luta e confronto necessários às mudanças" (p.22). Entretanto, pelo que sinaliza a visão dos jovens envolvidos, a negação ou reprovação de propostas tende a desqualificar sua atuação. Todavia, os sinais que emergem da fala da estudante mostram uma cobrança, uma necessidade do reconhecimento do grêmio, bem como, uma igualdade no caráter institucional.

Conforme nos dizem Corti e Souza (2004) “é no enfrentamento que será possível construir uma escola que responda de forma mais positiva aos anseios e necessidade dos jovens" (p.106). A fala da jovem, citada anteriormente, sinaliza que uma das tensões vividas junto à direção decorre, exatamente, de uma possível superioridade pleiteada por parte dos adultos, o que pode funcionar como um dificultador, ou mesmo, impeditivo de se estabelecer um bom relacionamento. Em contrapartida, é de vital importância o reconhecimento do conflito e da disputa como parte constitutiva da instituição grêmio estudantil, bem como, das experiências decorrentes da participação vivenciada em seu interior. A existência do grêmio como representante dos interesses dos estudantes gera tensão no interior da escola ao se digladiar com interesses divergentes também existentes na escola.

A forma de se estabelecer a discussão também é ponto importante. Dependendo do posicionamento, do tom de voz, dos argumentos, as coisas podem emperrar ou mesmo a razão pode mudar de lado. De acordo com Almeida (1998) um dos grandes motivos da falta de liberdade nas escolas é a falta de um espaço ao direito de contestar. Em se tratando do relacionamento com os jovens o diretor ressalta:

A minha relação para com eles é uma relação amistosa, é uma relação amistosa, desde que esse
indivíduo entenda o contrato social, que numa relação amistosa que estou observando o
contrato social, existem duas partes ou mais partes, então se o indivíduo chegar
educadamente comigo, conversando comigo educadamente, não interferindo na minha
fala ou não falando o que eu deva fazer, desde que chegue não me dando esses comandos,
não é verdade? Eu vou ter uma relação tranquila com esse indivíduo. (Diretor da Escola).

A fala do diretor nos permite inferir que existem aspectos particulares na relação jovens e direção, que os obstáculos e embargos estão para além das dificuldades da administração

\footnotetext{
${ }^{2}$ Grifos nossos.
} 
exclusivamente. De acordo Pescuma (apud CARLOS 2006) as relações existentes no interior da escola são centralizadoras e autoritárias. Nesse contexto, na escola por nós pesquisada, percebemos que na visão do diretor há uma forma de proceder por parte dos jovens, ou seja, uma hierarquia inserida em um "contrato social” e que está intimamente ligada ao respeito à fala da direção e a não cobrança de atitudes ou procedimentos, ou seja, dar "comandos". O que parece, é que tais divergências não se resumem somente ao que se refere à relação grêmio e direção, essas divergências podem refletir conflitos decorrentes do que Juarez Dayrell (2007) vai chamar de "relações intergeracionais", ou seja, a relação estabelecida entre o adulto e o jovem na escola, bem como, as diferenças e conflitos decorrentes dessa. São formas diferentes de lidar com as situações cotidianas, são experiências diferentes, tempos diferentes, vivências de vida de forma diferente.

Todavia, em se tratando do comportamento e atitudes dos jovens, nos parece que caso as coisas não aconteçam da forma que o diretor entende como adequadas, a tendência é que o processo se torne mais difícil, moroso e conturbado. Carlos (2006) menciona que "caso os grêmios ousem ir além (do que é visto como lícito pela direção), outros aparatos externos são acionados, com vistas a dificultar sua ação" (p.17). Tudo isso possivelmente usado como ferramenta de expressão de poder na relação estabelecida entre os jovens e a direção. Em relação ao fato, a fala de Nayara é esclarecedora, "ao meu ver, quando a gente faz reunião com a diretoria da escola, é assim, a gente fala tudo bem, mas o que tá certo é o que ele tá falando não o que a gente (...fala...), entendeu?A gente tem opinião, a gente pode falar, mas só o que tá certo é o que ele tá falando não a gente” (Nayara, 16 anos).Um ponto importante é reconhecermos a existência dessa hierarquia e, mais do que isso, seu devido respeito, entretanto, uma pergunta salta aos olhos: cobranças e divergências de opinião podem ser consideradas quebra de hierarquia? De acordo com Rodrigo "pro diretor os alunos têm que acatar as ordens da... de quem... da voz maior da escola" (Rodrigo, 16 anos), que nesse caso é a direção.

Sobre essa relação e a opinião do diretor a respeito do grêmio Felipe considera que o administrador não seja "muito a favor, porque o grêmio, ele é como muitas pessoas dizem, ele é contrário da direção, ele foi feito pra criticar, porque os alunos precisam disso, então, a direção sempre ficou com um pé atrás com a gente” (Felipe, 16 anos). Um problema que surge envolve as críticas feitas pelos jovens à direção e as possíveis dificuldades decorrentes dessas críticas. Haveria uma relação entre as críticas feitas e as dificuldades enfrentadas pelos jovens? Moreira (2001) em seu estudo ressalta que, geralmente, apesar do bom relacionamento com a direção nos momentos de conflito os jovens estudados por ele optaram pelo interesse dos estudantes.

Retomando a escola pesquisada, pudemos observar que mesmo diante dos aspectos anteriormente levantados, há, entre os jovens entrevistados, quem considere a atuação da direção como uma forma de contenção, com o intuito de evitar bagunça, Gabriel ressalta que "tem coisas que o 
diretor, às vezes, ele tenta fazer alguma forma de não barrar, mais tentar conter um pouco pra não, às vezes, não dar tumulto, não dar bagunça, ai ele tenta conter a gente um pouco nas coisas" (Gabriel, 17 anos). Na visão de Gabriel o embargo pode ser benéfico em alguns momentos.

O posicionamento dos jovens, no cerne das questões levantadas, torna-se um marco que delimita o início do convívio com ordens e lógicas diversas. A participação, ao que parece, ainda não é vista pelos jovens como processo gradual em que há avanços e retrocessos, em que se alcança degrau por degrau. É tudo ou nada! Tudo isso parece estar ligado a uma característica da condição juvenil vivida por eles. Há uma radicalidade inerente a vivência do presente de maneira urgente (DAYRELL, 2003, 2006). Essa visão tende a macular os avanços e conquistas e privilegiar o reconhecimento das “derrotas”. Entretanto, Moreira (2001) ressalta que as experiências vividas no grêmio possibilitam a apreensão de "conhecimentos e redes de relação que ajudam na formação pessoal, no sentido de um aprendizado para a vida" (p. 6). Ultrapassar essa visão radical e imediatista e reconhecer a virtude do que já foi feito pode demandar tempo e amadurecimento participativo.

Entre a posição dos jovens que se consideram como preteridos no processo participativo e a posição da direção que considera os jovens opositores e críticos, há uma disputa ininterrupta, que parece estar ligada a um processo gradual em que ambas as partes teriam que ceder em algum momento. Nesse aspecto, o exercício participativo pode vir a ser um mecanismo importante, um potencial dinamizador da lógica escolar e ao mesmo tempo um contribuinte para o processo formativo.

Ao final desse tópico, no que tange a relação estabelecida entre jovens gremistas e administração escolar, é de vital importância explicitar a percepção da ocorrência de duas ordens de tensão. A primeira coloca em oposição os alunos gremistas e a administração escolar como defensores de posicionamentos e interesses distintos. Essa tensão é inerente ao processo participativo, no qual o conflito é parte componente do grêmio e de sua existência na escola.

Em relação à segunda ordem de tensão, merece destaque o conflito intergeracional. A relação de poder se estabelece em outro nível, no qual a idade é critério de destaque. As falas do diretor, anteriormente mencionadas, evidenciam sua visão em relação aos jovens. Em alguns momentos é notória a desqualificação do aluno, tido por ele como imaturo, manipulável, incapaz de ter um pensamento próprio sem que um adulto esteja por trás. Segundo Debert (2000) ao dialogar com Fortes:

Nas sociedades ocidentais, a idade cronológica é estabelecida por um aparato cultural, um sistema de datação, independente e neutro em relação à estrutura biológica e a incorporação dos estágios de maturidade. Os critérios e normas da idade cronológica são impostos nas sociedades ocidentais não porque elas disponham de um aparato cultural que domina a reflexão sobre os estágios de maturidade, mas por exigência das leis que determinam os deveres e direitos do cidadão (DEBERT, 2000, p.57). 
Nesse sentido, a idade é critério legal para atuação dos jovens em determinadas situações. Essa idade legalizada tende a influenciar diversas instâncias sociais, como a escola, a família, dentre outras, em que os jovens são preteridos pela pouca idade e, consequentemente, pela falta de experiências de vida. Ao tratarmos dessa relação entre jovens gremistas e a administração da escola há que se considerar o forte caráter simbólico contido na idade. Essa situação sinaliza que ainda parece prevalecer para alguns adultos a visão do jovem como despreparado para certas atividades. Percebe-se a desqualificação da demanda emanada dos jovens. Na visão do adulto, esses seriam incapazes de propor, de sustentar sua proposição, de interagir com o meio. Assim, ao tratarmos da participação dos jovens na escola por meio do grêmio, devemos considerar também a intensidade desigual da relação de poder estabelecida entre os mais velhos e os mais novos.

\section{A RELAÇÃO COM OS PROFESSORES}

Assim como a relação com a direção da escola, a relação estabelecida entre os jovens do grêmio e seus professores tem um caráter singular no que concerne a influência na participação juvenil. No entanto, ao contrário do que ocorre com a direção, que é percebida pelos jovens como um “opositor" nas questões referentes ao grêmio, a relação estabelecida com os professores é, geralmente, de cordialidade, chegando algumas vezes a ser considerada de amizade.

Corti e Souza (2009), em pesquisa sobre juventude e ensino médio ${ }^{3}$, ressaltam que "apesar de todas estas dificuldades, verificamos que, de forma geral, os estudantes avaliam de maneira positiva seus professores e professoras" (p.36). Dayrell et. al. (2009), em um texto que dialoga com trabalhos que discutem a relação entre juventude e escola, salienta que em linhas gerais os jovens pesquisados nos trabalhos analisados "constatam a importância da qualidade da relação entre professor e aluno na aprendizagem dos alunos, o que os influencia tanto positiva quanto negativamente” (p.89).

No que diz respeito às questões relativas ao grêmio, Karine ressalta que "os professores, assim... são nossos maiores amigos (dos jovens) nessa situação, eles estão procurando ajudar mesmo, porque tem professor aqui que dá aula há bastante tempo aqui, que conhece a escola bem melhor que muita gente, por serem professores, por conviver com todos os alunos, acho que eles são nossos maiores amigos que a gente tem aqui agora" (Karine, 16 anos). A fala da jovem expressa a relação de amizade com os professores, mas também elucida um caráter de valorização desse ator em função da sua posição, de ter contato com todos os alunos e conhecer a escola. Garcia (apud Dayrell et. al. 2009) em seu trabalho ressalta que "na visão dos alunos, as características valorizadas no professor são a

\footnotetext{
${ }^{3}$ Pesquisa que tinha como objetivo elaborar diretrizes para políticas públicas de educação em escolas de ensino médio.
} 
afinidade, a sua atitude, que se refere ao jeito de ser e de interagir desse profissional e também a metodologia utilizada no cotidiano escolar" (p.90).

Tendemos a crer que isso se deve, em certa medida, ao contato estabelecido de forma mais cotidiana, quase diária, nas salas de aula. Isso pode funcionar como um mecanismo aproximador e facilitador do acesso para conversas e discussão sobre as mais variadas dúvidas dos jovens. Ao fazer uma comparação entre as relações estabelecidas com a direção e os professores, Andresa ressalta que "a atuação dos professores já é melhor, assim... eles têm mais interesse, eles falam, 'ó grêmio o quê que vocês estão fazendo', dão ideias até, é mais bacana a ligação com os professores e o grêmio" (Andresa, 16 anos).

O interesse dos professores, ressaltado pela jovem, é um ponto importante e pode sinalizar que essa relação, considerada boa pelos jovens, seja reflexo de uma valorização demonstrada pelos professores para com os estudantes. Já as críticas à direção, como por exemplo, a ausência e a distância em relação ao grêmio, podem se relacionar às dificuldades enfrentadas pelo diretor em lidar com a administração e o atendimento aos jovens. Em certa medida, isso pode ser um indicador de distanciamento da direção para com os temas relativos à participação dos jovens como tratamos em item anterior, ou mesmo, um demonstrativo da necessidade de buscar um maior contato.

Um outro fator que influencia a relação professor aluno é o ambiente em que se estabelece essa relação. A própria sala de aula torna-se lugar propício para o diálogo com os jovens. Dayrell nos diz que:

O cotidiano na sala de aula reflete uma experiência de convivência com a diferença. Independente dos conteúdos ministrados, da postura metodológica dos professores, é um espaço potencial de debate de ideias, confronto de valores e visões de mudo, que interfere no processo de formação e educação dos alunos (DAYRELL, 2006, p. 150).

Nesse espaço da sala pode proporcionar momentos em que o conteúdo das disciplinas pode dialogar com a prática. Gabriel, membro do grêmio entrevistado na pesquisa, comenta que "os professores sempre ajudam mesmo, conversam com a gente, assim... em sala, sempre envolve, assim... ajudam a gente a fazer alguma coisa que a gente tá tentando promover, sempre ajudam de uma forma ou de outra assim” (Gabriel, 17 anos). Dentre os docentes, Bruna destaca a atuação dos professores de História, de acordo com a jovem eles "empolgam um pouco né? Por causa que, é uma coisa mais de colocar, eu acho que eles tentam colocar passar pros alunos a ideia de que o mundo não tem que ser como eles querem, como que os outros querem que a gente seja. Eles falam que a gente tem colocar a nossa opinião, aí acho que os professores de historia são mais ativos assim por causa dessa opinião deles" (Bruna, 16 anos). 
Entretanto, os professores não são unanimidade na visão dos jovens. Existem uns mais próximos e outros menos próximos. Uns auxiliam e outros nem discutem as questões do grêmio. Nesse aspecto, a relação se constrói com base na reciprocidade e afinidade. Em contrapartida, os professores também não são todos unânimes quanto às atividades desenvolvidas pelos jovens no grêmio, bem como, com a forma como as coisas se desencadeiam. Alguns sinais podem refletir uma tendência do adulto em ver o jovem como alguém em processo de formação e que, portanto, precisa ser tutelado. Sobre esse tema a professora de inglês comenta: “eu acho que também tem que ter algum professor da escola disposto, algum adulto, percebe? Disposto a pontuar ali (no grêmio), por que senão eles acham que vão fazer de tudo, que pode fazer tudo" (Professora de Inglês).

Tal fala pode nos sinalizar que, para alguns professores, ainda prevalece um clima de insegurança diante da possibilidade de liberdade para os jovens. Nesse aspecto, prevalece também a visão do ator social em formação, ainda despreparado para o exercício da autonomia plena. Esse até pode exercitar a liberdade, todavia, de forma tutelada. Porém, fica um questionamento, em que medida essa tutela, que pode em certos momentos se tornar obstáculo, é bem aceita pelos jovens? Muitas vezes, os jovens, apesar de reconhecer a importância do aspecto institucional da participação, optam por formas menos burocráticas como voluntariado e grupos juvenis (Rap, Funck, Teatro, Skate, entre outros), por reconhecerem esses espaços como sendo mais autônomos e genuínos, estando ligados ao exercício da liberdade e por tratar dos interesses propriamente dos jovens (IBASE, 2006).

Em se tratando da relação que se estabelece entre os professores e os jovens do grêmio, a direção da escola considera que alguns professores, que fazem oposição a sua gestão, utilizam-se dos jovens para tal. Assim como alguns professores se aproximam dos jovens e outros são considerados afastados, cria-se a impressão que existem dois campos opostos, aqueles que apóiam a direção, que são mais afastados dos jovens, e aqueles que fazem oposição, que não são tão próximos dos jovens. Nesse processo o reconhecimento dos jovens, bem como, das ações do grêmio, se dá de forma diferente e parece ser influenciado pelo campo em que se encontra o professor, ou seja, posição ou oposição. $\mathrm{O}$ professor de História considera:

São jovens muito bons no sentido da resposta que eles dão aos desafios, do interesse deles em
aprender e melhorar e compreender que as questões políticas, questões sociais as quais estão
vinculados, algumas até muito duras né, algumas muito fortes pra eles, pra idade deles, é esse
respeito que a gente aprende a ter com o aluno trabalhador aqui do bairro. É um esforço muito
grande, é um esforço é... de energia muito grande, se deslocar do bairro pra trabalhar mesmo
que seja no Eldorado ou Belo Horizonte e retornar (...) pra estudar à noite. (Professor de
História).

A fala do professor é esclarecedora no que tange sua posição diante da participação dos jovens. Ele reconhece os interesses e aptidões desses jovens, salienta a busca de uma compreensão do que está 
acontecendo politicamente no país e mais do que isso reconhece as dificuldades vividas pelos estudantes que trabalham. Já a professora de inglês considera que:

Olha, são jovens que têm, me parece assim, uma sede muito grande de mudança, dessa pasmaceira que a escola tem, mas não sabem como é que faz isso. Eles querem expressar as suas ideias cheias de emoções, com seus sentimentos, e tudo, mas ainda estão bem perdidos. Com relação à questão da maturidade, parece que eles às vezes querem ser mais maduros do que na verdade são. (Professora de Inglês).

A professora, apesar de reconhecer a sede de mudança dos jovens, destaca o aspecto emocional dos jovens como algo ruim, que os leva a ficarem perdidos, além disso, acrescenta o aspecto da imaturidade como um impeditivo para a participação. Se o reconhecimento se dá de formas diferentes por parte dos professores, os jovens também deixam claro sua opinião a respeito dos docentes. Ao contrário do que poderia indicar uma visão romantizada sobre os jovens gremistas e sua relação com os professores, percebemos que as coisas não são um mar de rosas e que existem diferenças pontuais no ato de se relacionar que variam de acordo com os alunos e professores envolvidos.

Os jovens pesquisados, em sua maioria, ressaltam que o papel do professor, de acordo com seus procedimentos e práticas, é importante, é singular, e pode influenciar nos rumos tomados no processo de participação do estudante. De acordo com Corti e Souza (2009) "a expectativa que os educadores nutrem sobre os educandos é um fator crucial para o desenvolvimento da aprendizagem, afinal, sem esperar muito dos alunos, provavelmente os professores não irão desafiá-los o suficiente para aprenderem" (p.36).

Conforme nos mostram Dayrell e Barbosa (2009) "os jovens demonstram respeitar e aceitar muito mais os professores que discutiam sobre a vida além dos muros da instituição do que os educadores que, segundo eles, "só dão matéria"” (p.243). Rodrigo, ao tratar da relação entre os professores e os jovens do grêmio e do potencial exercício participativo nas disciplinas, salienta que "o professor faz a matéria se tornar legal ou chata, tem professor que você nem conversa certas questões" (Diário de Campo - março de 2009).

Portanto, fica evidente que, em relação à participação dos jovens e sua exacerbada responsabilização para com esse processo, há que se considerar a existência de outros atores com potencial responsabilidade e que podem contribuir, em maior ou menor grau, no aprimoramento do papel do estudante como efetivo participante no processo educacional.

\section{CONSIDERAÇÕES FINAIS}

Diante do exposto, retomamos a relação estabelecida entre os jovens estudantes, a direção e os professores no cotidiano da escola. Em relação à direção da escola e o grêmio, percebe-se que a 
existência de conflitos reflete a defesa de pontos de vista opostos. A lógica escolar e a dinâmica dos jovens tendem a ser dissonantes. São formas distintas no lidar com o tempo e o espaço. A negociação pode ser uma saída, mas o conflito é inerente a esse processo e está intrinsecamente ligado à disputa pelos interesses díspares.

O avanço e o recuo, o vencer e o perder, são situações salutares. Ao contrário do que comumente se diz - que o consenso é a melhor saída - pensamos que o conflito nesse caso foi uma fonte importante para a dinâmica escolar e para o reconhecimento dos novos sujeitos. Entretanto, há que se ressaltar que a instituição escolar, da forma como se encontra organizada normalmente, privilegiando as aulas em sala, os tempos rígidos, uma atuação burocrática, tende em obstaculizar o jovem em sua participação e em seu processo de formação mais ampla. A participação ainda não é vista como sendo inerente ao processo formativo educacional.

Para além dos conflitos na esfera institucional, há que se considerar também as relações intergeracionais. Ao que parece, ainda prevalece um olhar infantilizado para com o jovem na escola estudada. Uma desqualificação que destaca a incapacidade do jovem em resolver seus problemas. Mais do que isso, cria uma dependência em relação ao adulto que, muitas vezes, ao manter os projetos e demandas guardados na gaveta da mesa, dificulta a atuação dos jovens. A juventude vista, simplesmente, em sua imaturidade, radicalidade e transição, coloca por terra seu caráter inovador, sua capacidade de romper, de mudar.

Nesse contexto, nossas observações demonstram claramente que o poder, desigualmente distribuído, está majoritariamente nas mãos dos adultos, principalmente, em função da idade e do lugar ocupado na hierarquia escolar. Tal fato pode funcionar como obstáculo para uma participação efetiva dos jovens estudantes no cotidiano da escola. 


\section{REFERÊNCIAS}

ABRAMO, Helena. Participação e organizações juvenis. Recife: Projeto Redes de Juventude, 2004.

ALMEIDA, Marcello Ricardo. Ignorância do estudante: Filosofia do Direito Estudantil. Santa Catarina: Odorizzi, 1998.

ARROYO, Miguel . Imagens Quebradas. Petrópolis: Vozes, 2005.

BESSA, Valéria da Hora et. al. Grêmio Estudantil: um dispositivo para a participação dos alunos na gestão do processo escolar. [s.n.t.].

CARLOS, Aparecida da Graça. "Grêmio Estudantil e Participação do Estudante”. 2006. Dissertação (Mestrado em Educação) - Faculdade de Educação da Pontifícia Universidade Católica de São Paulo (PUC-SP), 2006.

CORTI, Ana Paula; SOUZA, Raquel. Diálogos com o mundo juvenil: subsídios para educadores. São Paulo: Ação educativa, 2004.

CORTI, Ana Paula; SOUZA, Raquel . Que ensino médio queremos? Pesquisa quantitativa e grupos de diálogo sobre ensino médio. São Paulo: Ação Educativa, 2009.

DAYRELL, Juarez. O jovem como sujeito social. Revista Brasileira de Educação, São Paulo, $\mathrm{n}^{\circ} 24$ set./ dez., 2003.

DAYRELL, Juarez. A escola como espaço sócio-cultural. In: (org.). Múltiplos olhares sobre educação e cultura. Belo Horizonte: UFMG, 2006.

DAYRELL, Juarez. A Escola "faz" as juventudes? Reflexões em torno da socialização juvenil. In. VIEIRA, Maria Manuel (org.). Atores educativos: escola, jovens, e media. Lisboa: Imprensa de Ciências Sociais, 2007.

DAYRELL, Juarez et. al.. Juventude e Escola. In. SPOSITO, Marília (coord.). O Estado da Arte sobre juventude na pós-graduação brasileira: educação, ciências sociais e serviço social (1999-2006). Belo Horizonte: Argumentum, 2009. (vol. 1).

DAYRELL, Juarez; BARBOSA, Daniele. “Turma ou panelinha?”: a sociabilidade de jovens alunos em uma escola pública. In. SOARES, Leôncio; SILVA, Isabel de Oliveira (org.). Sujeitos da educação e processos de sociabilidade: os sentidos da experiência. Belo Horizonte: Autêntica, 2009.

DEBERT, Guita Grin. Antropologia e o estudo dos grupos e das categorias de idade. In. BARROS, Myriam Moraes Lins de (org.). Velhice ou terceira idade? Estudos antropológicos sobre identidade, memória e política. Rio de Janeiro: Editora FGV, 2000.

GIDDENS, Antony. Modernidade e identidade. Rio de Janeiro: Jorge Zahar, 2002.

IBASE. Juventude brasileira e democracia: participação, esferas e políticas públicas. Relatório Global. Rio de janeiro: Ibase, janeiro de 2006. 
MARTINS, Francisco André Silva. Juventude, Grêmio Estudantil e Ação Coletiva: considerações em torno dos movimentos sociais na contemporaneidade. Encontro dos Pesquisadores em Educação dos Programas de Pós-Graduação UFMG/PUC-MG/UEMG/CEFET-MG. Belo Horizonte, Junho de 2009.

MELUCCI, Alberto. Um objetivo para os movimentos sociais? Revista Lua Nova. São Paulo, nº17, 1989.

MELUCCI, Alberto. A invenção do presente. Petrópolis: Vozes, 2001.

MELUCCI, Alberto. O jogo do eu. São Leopoldo: Unisinos, 2004.

MOREIRA, Marco Antônio. Grêmios Estudantis: contestação e distinção social. Rio de Janeiro: Papel Virtual, 2001.

OLIVEIRA, Dalila Andrade (org.). Gestão Democrática da Educação: desafios contemporâneos. Petrópolis: Vozes, 2006.

RAMOS, Jannette Filomeno Pouchain. Gestão Democrática da Escola Pública: a experiência do governo das mudanças. Fortaleza: UECE, 2005.

SACRISTAN, José Gimeno. O aluno como invenção. Porto Alegre: Artmed Editora, 2005. 